\title{
Microdetermination of Sialic Acids in Blood Samples by Hydrophilic Interaction Chromatography Coupled to Post-column Derivatization and Fluorometric Detection
}

\author{
Yuko NAGAI, Iori SAKAKIBARA, and Hidenao TOYODA ${ }^{\dagger}$ \\ Faculty of Pharmaceutical Sciences, Ritsumeikan University, 1-1-1 Nojihigashi, Kusatsu, Shiga 525-8577, Japan
}

\begin{abstract}
An analytical method for the determination of sialic acids in biological samples has been developed and applied to fetal bovine serum (FBS), newborn calf serum and adult bovine serum. The hydrolysis of sera was carried out and the liberated sialic acids were quantified using a rapid and sensitive HPLC. The HPLC includes the separation and detection of $\mathrm{N}$-acetylneuraminic acid (Neu5Ac) and $\mathrm{N}$-glycolylneuraminic acid (Neu5Gc) using hydrophilic interaction liquid chromatography and a fluorometric post-column reaction with 2-cyanoacetamide. The calibration graphs for Neu5Ac and Neu5Gc were linear over the range of $10 \mathrm{pmol}-5 \mathrm{nmol}$. The concentrations of sialic acids in FBS, newborn calf serum and adult bovine serum were 5.06, 3.79 and $1.64 \mathrm{mM}$, respectively. The ratios of Neu5Gc and Neu5Ac changed dramatically according to the development stages. The present method has a satisfactory sensitivity in the quantification of Neu5Ac and Neu5Gc in serum samples. It seems that this analytical system can therefore be applied for routine use in clinical investigations of serum sialylation changes in cancer patients.
\end{abstract}

Keywords Sialic acids, serum, cancer biomarker, HPLC, fluorometric detection

(Received November 15, 2018; Accepted December 20, 2018; Advance Publication Released Online by J-STAGE December 28, 2018)

\section{Introduction}

It is very important to establish a sensitive and accurate analytical method to clarify the role of sialic acids in biological samples. The sialic acids, which are acylated derivatives of neuraminic acid, are widely distributed in nature as components of oligosaccharide units in glycoconjugates. Sialic acids present in humans and animals are mainly Neu5Ac and Neu5Gc.

Sialic acids are an important group of monosaccharides regarding cancer-associated glycan changes. Several workers reported the importance of measuring sialic acid levels in serum or plasma as a marker in various types of cancer. ${ }^{1,2}$ Humans are unable to synthesize Neu5Gc., ${ }^{3,4}$ Despite this fact, Neu5Gc has been found on human epithelial and endothelial cell surfaces as a result of incorporation from dietary sources. ${ }^{5}$ Furthermore, Neu5Gc is associated with cancer pathologies, and elevated levels have been detected in various types of cancer, such as colorectal cancer, liver cancer and ovarian cancer. ${ }^{6-9}$ Thus, a simultaneous analysis of Neu5Ac and Neu5Gc in biological samples may be useful for the diagnosis, treatment and investigation of those diseases.

The quantitative determination of sialic acids has been performed by colorimetry ${ }^{10,11}$ and fluorometry. ${ }^{12,13}$ Those colorimetric methods using thiobarbituric acid have been most widely used for the total sialic acid values (usually the sum of Neu5Ac and Neu5Gc). However, the method is not selective or sensitive for sialic acids, and suffers interference from 2-deoxyglucose and 2-deoxyribose. Simultaneous determinations

$\dagger$ To whom correspondence should be addressed.

E-mail: hidenao@ph.ritsumei.ac.jp of sialic acids by gas chromatography, ${ }^{14}$ gas chromatography mass spectrometry ${ }^{15}$ and HPLC with UV detection ${ }^{16}$ have been developed, and determinations of Neu5Ac and Neu5Gc have been carried out. Fluorometric HPLC methods with precolumn derivatization using either $4^{\prime}$-hydrazino-2-stilbazole, ${ }^{17}$ 1,2-diamino4,5-methylenedioxybenzene dihydrochloride (DMB), ${ }^{18} o$-phenylenediamine dihydrochloride ${ }^{19}$ or 4-( $N, N$-dimethylaminosulfonyl)7-piperazino-2,1,3-benzoxadiazole ${ }^{20}$ have been developed for the sensitive determination of sialic acids. One of the most common fluorescence labels for sialic acids is DMB, which is often used in HPLC separation and fluorescence detection ${ }^{18,21}$ as well as liquid chromatography electrospray ionization mass spectrometry. ${ }^{22,23}$ HPLC separation following post-column derivatization is an automatic method for monosaccharides and oligosaccharides. For sialic acids, anion-exchange chromatography with post-column derivatization using malononitrile following fluorometric detection ${ }^{24}$ and sodium hydroxide following pulsed amperometric detection ${ }^{25}$ have been reported. Although 2-cyanoacetamide (2-CA) is a useful postcolumn reagent for the determination of acidic sugars as well as neutral and amino sugars, ${ }^{26,27}$ it has been reported that $2-\mathrm{CA}$ is not suitable for the sensitive analysis of sialic acids. ${ }^{24}$

In this study, we developed a rapid and sensitive method for the determination of Neu5Ac and Neu5Gc by a new fluorometric post-column HPLC technique. This method was then applied to the analysis of age-related changes in bovine serum sialic acids.

\section{Experimental}

Materials and reagents

Neu5Ac and Neu5Gc were obtained from Tokyo Chemical 


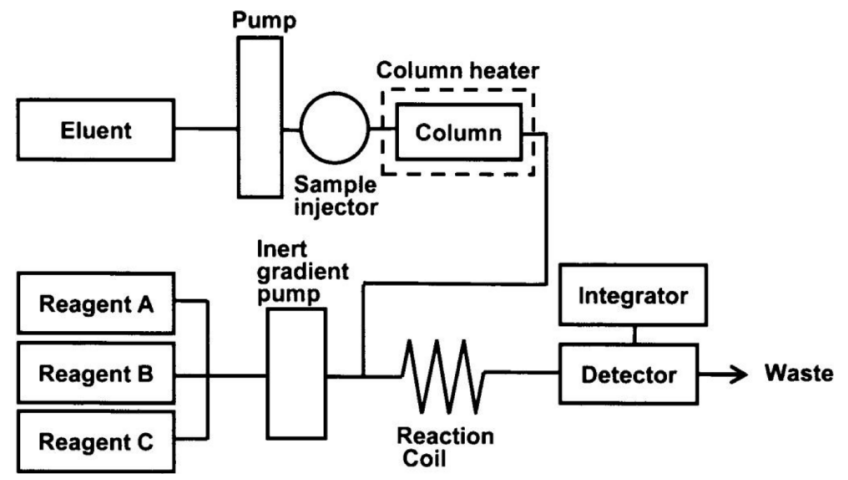

Fig. 1 Flow diagram of the post-column HPLC system for the determination of sialic acids. Column, InertSustain Amide $(2.1 \mathrm{~mm}$ i.d. $\times 250 \mathrm{~mm})$ at $60^{\circ} \mathrm{C}$; eluent, acetonitrile/water $/ 0.2 \mathrm{M}$ sodium phosphate buffer ( $\mathrm{pH} 2.0) / 3.0 \mathrm{M}$ ammonium chloride (100/24/1/1); reagent $\mathrm{A}, \mathrm{H}_{2} \mathrm{O}$; reagent $\mathrm{B}, 1 \%(\mathrm{w} / \mathrm{v}) 2-\mathrm{CA}$; reagent $\mathrm{C}, 1.0 \mathrm{M}$ sodium hydroxide; reaction temperature, $120^{\circ} \mathrm{C}$; excitation, $331 \mathrm{~nm}$; emission, $383 \mathrm{~nm}$. Injection volume, $5 \mu \mathrm{L}$. Other conditions as described in the text.

Industry (Tokyo, Japan). A centrifugal ultrafiltration membrane, NANOSEP 3K OMEGA (for volumes up to $500 \mu \mathrm{L}$ and $3 \mathrm{~K}$ normal molecular weight limit) was obtained from Pall Life Science (Ann Arbor, MI). FBS, newborn calf serum, adult bovine serum and 2-CA were obtained from Sigma-Aldrich (St. Louis, MO). An InertSustain Amide column (2.1 mm i.d. $\times$ $250 \mathrm{~mm}$; particle size $5 \mu \mathrm{m}$ ), was obtained from GL Sciences (Tokyo, Japan). All other chemicals used were of analytical reagent grade.

\section{Apparatus and HPLC conditions}

For sialic acids analysis, the chromatographic equipment included pumps (PU-4180 for eluent; PU-2089i Plus for reagent solutions), a fluorescence spectrophotometer (FP-2025 Plus) from Jasco (Tokyo, Japan), a chromato-integrator (D-2500) from Hitachi (Tokyo, Japan), a sample injector with a $20-\mu \mathrm{L}$ loop (Model 7725i) from Reodyne (CA, USA), a column heater (Thermo Minder SDmini) from Taitec (Saitama, Japan) and a dry reaction bath (DB-5) from Shimamura Instrument (Tokyo, Japan).

The HPLC conditions were established as follows (Fig. 1): an InertSustain Amide column $(2.1 \mathrm{~mm}$ i.d. $\times 250 \mathrm{~mm})$ was eluted isocratically with an acetonitrile/water/0.2 $\mathrm{M}$ sodium phosphate buffer ( $\mathrm{pH} 2.0) / 3.0 \mathrm{M}$ ammonium chloride (100/24/1/1) at a flow-rate of $0.4 \mathrm{~mL} / \mathrm{min}$ (column temperature, $60^{\circ} \mathrm{C}$ ). A reagent was added to the effluent by using an inert gradient pump, PU-2089i Plus, at a flow-rate of $0.4 \mathrm{~mL} / \mathrm{min}$. The following reagents were used: reagent $\mathrm{A}$, water; reagent $\mathrm{B}, 1 \%(\mathrm{w} / \mathrm{v}) 2-\mathrm{CA}$; reagent $\mathrm{C}, 1.0 \mathrm{M}$ sodium hydroxide. The mixing ratio for the reagents was as follows: reagent $\mathrm{A}, 25 \%$; reagent $\mathrm{B}, 50 \%$; reagent $\mathrm{C}, 25 \%$. The mixture of the effluent and the reagent passed through a polytetrafluoroethylene (PTFE) reaction coil $(0.5 \mathrm{~mm}$ i.d. $\times 7 \mathrm{~m})$ set in a dry reaction bath controlled at $120^{\circ} \mathrm{C}$, and then through a PTFE cooling coil $(0.25 \mathrm{~mm}$ i.d. $\times$ $3 \mathrm{~m}$ ). The effluent was monitored fluorometrically (excitation, $331 \mathrm{~nm}$; emission, $383 \mathrm{~nm}$ ). The sample was dissolved in $75 \%(\mathrm{v} / \mathrm{v})$ acetonitrile and a $5-\mu \mathrm{L}$ aliquot was loaded onto the HPLC.

\section{Analysis of serum sialic acids}

Five microliters of serum was heated at $80^{\circ} \mathrm{C}$ for $2 \mathrm{~h}$ with $45 \mu \mathrm{L}$ of $55 \mathrm{mM}$ hydrochloric acid. The hydrolysate was

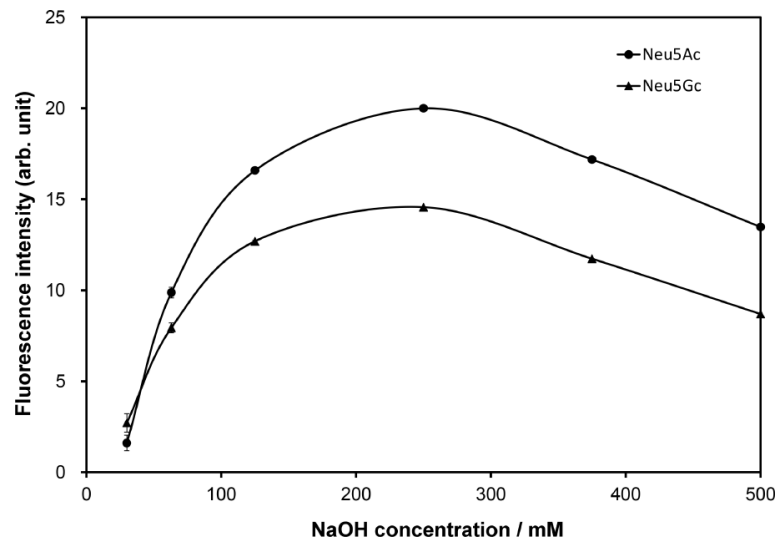

Fig. 2 Effect of the sodium hydroxide concentration in the reagent mixture. Injection volume, $5 \mu \mathrm{L}$ ( $200 \mathrm{ng}$ of each sugar). The error bars represent the standard deviations $(n=3)$.

applied to the centrifugal ultrafiltration membrane. Twenty microliters of the flow through was evaporated, and then the sample was resuspended in $15 \mu \mathrm{L}$ of $75 \%(\mathrm{v} / \mathrm{v})$ acetonitrile and centrifuged at $13000 \times g$ for 5 -min. A $5-\mu \mathrm{L}$ aliquot of the sample solution was loaded onto the post-column HPLC.

\section{Results and Discussion}

\section{Separation and detection of sialic acids}

The standards Neu5Ac and Neu5Gc have been separated with hydrophilic interaction liquid chromatography (HILIC). Aminobonded silica has been one of the most commonly used packings for the separation of oligosaccharides. However, this support is chemically unstable, and its lifetime is relatively short. ${ }^{28}$ An amide-bonded silica column has the advantage of high stability compared with the amino-bonded silica column, and has additional properties that permit the resolution of acidic sugars. ${ }^{29}$ In a previous study, we tried the separation of unsaturated disaccharides including both carboxy residue and sulfate residue by using an amide-bonded silica column. Ammonium chloride improved the separation of unsaturated disaccharides. The $\mathrm{pHs}$ of the buffer in the mobile phases affected the separation, and weak alkaline condition was suitable for unsaturated disaccharides. Therefore, the upper $\mathrm{pH}$ limit at $60^{\circ} \mathrm{C}(\mathrm{pH} 7)$ was employed. ${ }^{29}$ Ammonium chloride was also an effective salt for the separation of Neu5Ac and Neu5Gc. However, the buffer solution ( $\mathrm{pH} 7$ ) gave broad and tailing peaks. Acidic conditions considerably improved sialic acid separation, and a lower $\mathrm{pH}$ limit at $60^{\circ} \mathrm{C}(\mathrm{pH} 2)$ was selected for the buffer in the mobile phase. Using an amide-bonded silica column, the conditions were investigated to successfully determine the appropriate isocratic conditions to resolve Neu5Ac, Neu5Gc and biological interferences.

A fluorometric post-column method with 2-CA was employed for specific and sensitive detection. The post-column reagent system used in this study was improved by an inert gradient pump, and high sensitivity was achieved under strongly alkaline conditions. In order to obtain higher reactivity, the reaction conditions were optimized using a standard solution of sialic acids. The concentration of sodium hydroxide in the reagent mixture was investigated over the range of $30-500 \mathrm{mM}$, and the maximum fluorescence intensity was obtained at a concentration of $250 \mathrm{mM}$ (Fig. 2). 
Table 1 Validation results for the determination of Neu5Ac and Neu5Gc

\begin{tabular}{|c|c|c|c|c|c|c|c|}
\hline Compound & Concentration $/ \mu \mathrm{M}$ & Intra-day RSD, \% & Inter-day RSD, \% & LOD/pmol & LOQ/pmol & Range & $r$ \\
\hline \multirow[t]{3}{*}{ Neu5Ac } & 2 & 3.86 & 4.96 & 1.5 & 10 & $10 \mathrm{pmol}-5 \mathrm{nmol}$ & 0.9998 \\
\hline & 10 & 2.65 & 3.64 & & & & \\
\hline & 100 & 2.30 & 3.15 & & & & \\
\hline \multirow[t]{3}{*}{ Neu5Gc } & 2 & 3.79 & 4.85 & 1.7 & 10 & $10 \mathrm{pmol}-5 \mathrm{nmol}$ & 0.9997 \\
\hline & 10 & 3.47 & 4.51 & & & & \\
\hline & 100 & 1.88 & 2.88 & & & & \\
\hline
\end{tabular}

Injection volume, $5 \mu \mathrm{L}(n=4)$.

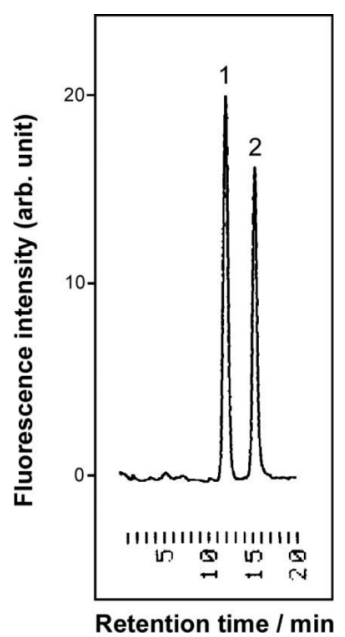

Fig. 3 Typical chromatogram of standard sialic acids. Injection volume, $5 \mu \mathrm{L}$ (200 ng of each sugar). Peaks: 1, Neu5Ac; 2, Neu5Gc. Other conditions as in Fig. 1.

\section{Method validation}

The repeatability, sensitivity, and linearity of the proposed method were examined using the standard Neu5Ac and Neu5Gc solutions (Table 1). The intra- and inter-assay precision of the standard solution of Neu5Ac and Neu5Gc resulted in relative standard deviations (RSD) of 2.30-4.96 and 1.88-4.85\%, respectively. The sensitivity was determined by measuring the limit of detection (LOD) and limit of quantitation (LOQ). The calibration graphs of sialic acids were linear from 10 pmol to 5 nmol. The correlation coefficients were $r=0.9998$ for Neu5Ac and $r=0.9997$ for Neu5Gc. The LOD $(S / N=3)$ was $1.5 \mathrm{pmol}$ for Neu5Ac and 1.7 pmol for Neu5Gc (Fig. 3). The proposed method was 100-times more sensitive than the previously reported method employing anion-exchange chromatography followed by post-column derivatization with malononitrile. ${ }^{24}$

\section{Hydrolysis condition}

Analyses of sialic acids in bovine sera were performed by HPLC according to the method in this study. Sialic acids have normally been liberated from biological samples by acid hydrolysis or neuraminidase digestion. However, when serum was treated with neuraminidase, only about $70 \%$ of the sialic acids were liberated, even under the optimum reaction

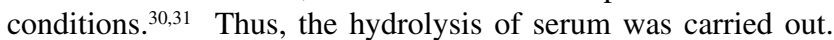
As a standard condition, the liberation of Neu5Ac and Neu5Gc from sera is performed in $25 \mathrm{mM}$ sulfuric acid at $80^{\circ} \mathrm{C}$ for $1 \mathrm{~h} .{ }^{17,18}$ The protocol in this study requires the removal of acids by evaporation. Therefore, hydrochloric acid was used rather than sulfuric acid. The liberation of sialic acids from sera was

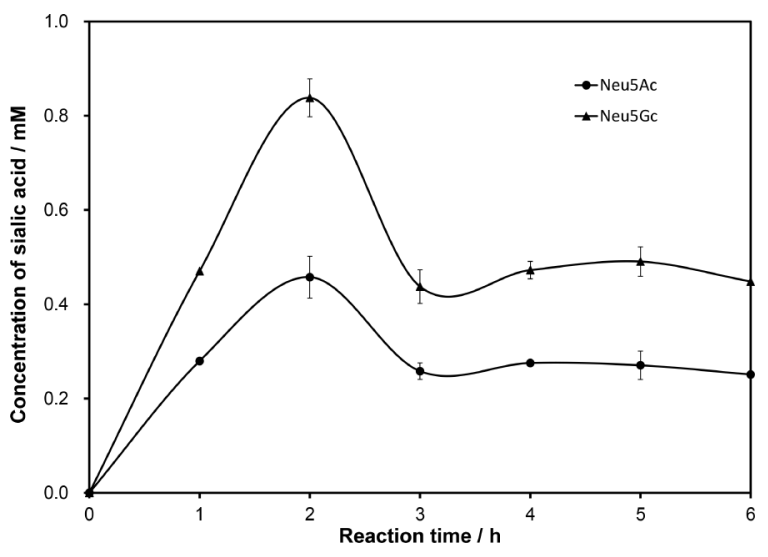

Fig. 4 Effect of hydrolysis time on the amount of Neu5Ac and Neu5Gc from adult bovine serum. Portions $(5 \mu \mathrm{L})$ of the serum samples were treated and analyzed by the post-column HPLC described in Fig. 1. The error bars represent the standard deviations $(n=3)$.

Table 2 Recovery rate from sera

\begin{tabular}{llrr}
\hline & & \multicolumn{1}{c}{ Added/0.1 mM } & \multicolumn{1}{c}{ Added/5 mM } \\
\cline { 3 - 4 } & Serum & \multicolumn{2}{c}{ Recovery, \% } \\
\hline \multirow{2}{*}{ Neu5Ac } & Fetal & $96.5 \pm 4.9^{\mathrm{a}}$ & $104.8 \pm 4.2$ \\
& Neuborn & $99.2 \pm 5.8$ & $96.6 \pm 3.4$ \\
& Adult & $98.6 \pm 6.8$ & $101.9 \pm 4.5$ \\
Neu5Gc & Fetal & $99.5 \pm 6.1$ & $104.6 \pm 4.6$ \\
& Neuborn & $98.7 \pm 5.4$ & $95.9 \pm 4.6$ \\
& Adult & $103.5 \pm 5.3$ & $102.3 \pm 5.6$ \\
\hline
\end{tabular}

a. Mean $\pm \mathrm{SD}(n=3)$.

completed by heating at $80^{\circ} \mathrm{C}$ for $2 \mathrm{~h}$ in $50 \mathrm{mM}$ hydrochloric acid (Fig. 4). Although the analyses may be affected by various contaminants in the sera, the hydrolysates were filtered through a centrifugal ultrafiltration membrane before evaporation.

\section{Sialic acids in bovine sera}

To confirm the adaptability, Neu5Gc and Neu5Ac were added to serum samples for measurements. The experimental results are summarized in Table 2. The recovery rates of Neu5Ac and Neu5Gc (0.1 and $5 \mathrm{mM}$ added) from sera were $96.5-104.8$, and $95.9-104.6 \%$, respectively. Typical chromatograms obtained from FBS, newborn calf serum and adult bovine serum are shown in Fig. 5. The analytical results are given in Table 3. The concentration of total sialic acids in FBS, newborn calf serum and adult bovine serum were 5.06, 3.79 and $1.64 \mathrm{mM}$ 


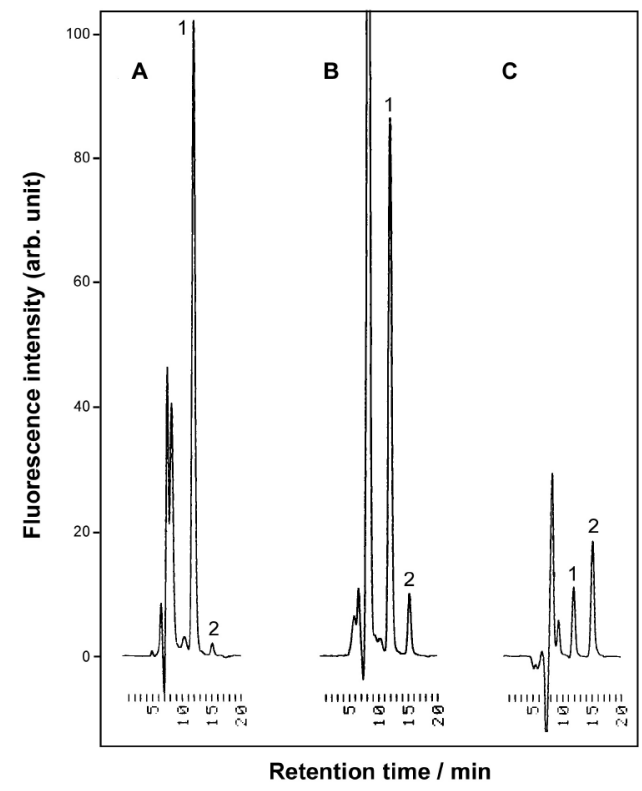

Fig. 5 Age-related changes in bovine serum sialic acids. A, FBS; B, newborn calf serum; $\mathrm{C}$, adult bovine serum. Peaks: 1, Neu5Ac; 2 , Neu5Gc. Other conditions as in Fig. 1.

Table 3 Concentration of sialic acids in bovine sera

\begin{tabular}{lccc}
\hline Serum & $\begin{array}{c}\text { Neu5Ac/ } \\
\mathrm{mM}\end{array}$ & $\begin{array}{c}\text { Neu5Gc/ } \\
\mathrm{mM}\end{array}$ & $\begin{array}{c}\text { Neu5Gc/ } \\
\text { Neu5Ac }\end{array}$ \\
\hline Fetal & $4.93 \pm 0.38^{\mathrm{a}}$ & $0.13 \pm 0.01$ & 0.03 \\
Newborn & $3.32 \pm 0.44$ & $0.47 \pm 0.08$ & 0.14 \\
Adult & $0.58 \pm 0.04$ & $1.06 \pm 0.09$ & 1.83 \\
\hline
\end{tabular}

a. Mean $\pm \operatorname{SD}(n=3)$.

respectively. The ratios of Neu5Gc and Neu5Ac changed dramatically according to the development stages. The results were almost identical to the published data. , $^{18,32}$

\section{Conclusions}

Sialic acids were determined by a HILIC separation with sensitive and specific post-column detection. A post-column HPLC for the determination of sialic acids by monitoring the fluorescence produced with malononitrile has been reported. A measurement of the fluorescence intensity allowed for the determination of $3-60 \mathrm{nmol}$ of sialic acids. ${ }^{24}$ The present postcolumn HPLC with 2-CA has a satisfactory sensitivity in the quantification of Neu5Ac and Neu5Gc in serum samples (calibration graphs were linear in the range $10 \mathrm{pmol}-5 \mathrm{nmol}$ ). In this study, only $5 \mu \mathrm{L}$ of serum was used for a precise analysis. Serum sialic acids in cancer patients have been reported to change both in quality and quantity. ${ }^{2}$ It seems that our analytical system can therefore be applied for routine use in clinical investigations of serum sialylation changes in cancer patients.

\section{References}

1. B. Adamczyk, T. Tharmalingam, and P. M. Rudd, Biochim.
Biophys. Acta, 2012, 1820, 1347.

2. Z. Zhang, M. Wuhrer, and S. Holst, Glycoconj. J., 2018, 35, 139.

3. E. A. Muchmore, S. Diaz, and A. Varki, Am. J. Phys. Anthropol., 1998, 107, 187.

4. A. Irie, S. Koyama, Y. Kozutsumi, T. Kawasaki, and A. Suzuki, J. Biol. Chem., 1998, 273, 15866.

5. F. Alisson-Silva, K. Kawanishi, and A. Varki, Mol. Aspects Med., 2016, 51, 16.

6. H. Higashi, Y. Hirabayashi, Y. Fukui, M. Naiki, M. Matsumoto, S. Ueda, and S. Kato, Cancer Res., 1985, 45, 3796.

7. T. Kawai, A. Kato, H. Higashi, S. Kato, and M. Naiki, Cancer Res., 1991, 51, 1242.

8. T. Koda, M. Aosasa, H. Asaoka, H. Nakaba, and H. Matsuda, Int. J. Clin. Oncol., 2003, 8, 317.

9. S. L. Diaz, V. Padler-Karavani, D. Ghaderi, N. HurtadoZiola, H. Yu, X. Chen, E. C. Brinkman-Van der Linden, A. Varki, and N. M. Varki, PLoS One, 2009, 4, e4241.

10. L. Warren, J. Biol. Chem., 1959, 234, 1971.

11. D. Aminoff, Biochem. J., 1961, 81, 384.

12. K. S. Hammond and D. S. Papermaster, Anal. Biochem., 1976, 74, 292.

13. J. Murayama, M. Tomita, A. Tsuji, and A. Hamada, Anal. Biochem., 1976, 73, 535.

14. R. Schauer, Methods Enzymol., 1978, 50, 64.

15. I. Mononen and J. Kärkkäinen, FEBS Lett., 1975, 59, 190.

16. A. K. Shukla, N. Scholz, E. H. Reimerdes, and R. Schauer, Anal. Biochem., 1982, 123, 78.

17. K. Kobayashi, Y. Akiyama, K. Kawaguchi, S. Tanabe, and T. Imanari, Anal. Sci., 1985, $1,81$.

18. S. Hara, Y. Takemori, M. Yamaguchi, M. Nakamura, and Y. Ohkura, Anal. Biochem., 1987, 164, 138.

19. K. R. Anumula, Anal. Biochem., 1995, 230, 24.

20. A. Kawasaki, M. Yasuda, K. I. Mawatari, T. Fukuuchi, N. Yamaoka, K. Kaneko, R. Iijima, S. Yui, M. Satoh, and K. Nakagomi, Anal. Sci., 2018, 35, 841.

21. T. Hikita, K. Tadano-Aritomi, N. Iida-Tanaka, H. Toyoda, A. Suzuki, T. Toida, T. Imanari, T. Abe, Y. Yanagawa, and I. Ishizuka, Anal. Biochem., 2000, 281, 193.

22. A. Klein, S. Diaz, I. Ferreira, G. Lamblin, P. Roussel, and A. E. Manzi, Glycobiology, 1997, 7, 421.

23. F. Priego-Capote, M. I. Orozco-Solano, M. CalderónSantiago, and M. D. Luque de Castro, J. Chromatogr. A, 2014, 1346, 88.

24. S. Honda, S. Iwase, S. Suzuki, and K. Kakehi, Anal. Biochem., 1987, 160, 455.

25. A. E. Manzi, S. Diaz, and A. Varki, Anal. Biochem., 1990, $188,20$.

26. S. Honda, Y. Matsuda, M. Takahashi, and K. Kakehi, Anal. Chem., 1980, 52, 1079.

27. H. Toyoda, K. Shinomiya, S. Yamanashi, I. Koshiishi, and T. Imanari, Anal. Sci., 1988, 4, 381.

28. H. Kutsuna, Y. Ohtsu, and M. Yamaguchi, J. Chromatogr. A, 1993, 635, 187.

29. H. Toyoda, T. Nagashima, R. Hirata, T. Toida, and T. Imanari, J. Chromatogr. B, 1997, 704, 19.

30. E. G. Trams and C. J. Lauter, Biochim. Biophys. Acta, 1962, 60, 350 .

31. S. Hakomori and T. Saito, Biochemistry, 1969, 8, 5082.

32. A. P. Sherblom, S. Bharathan, P. J. Hall, R. M. Smagula, C. E. Moody, and G. W. Anderson, Int. J. Biochem., 1988, 20, 1177. 